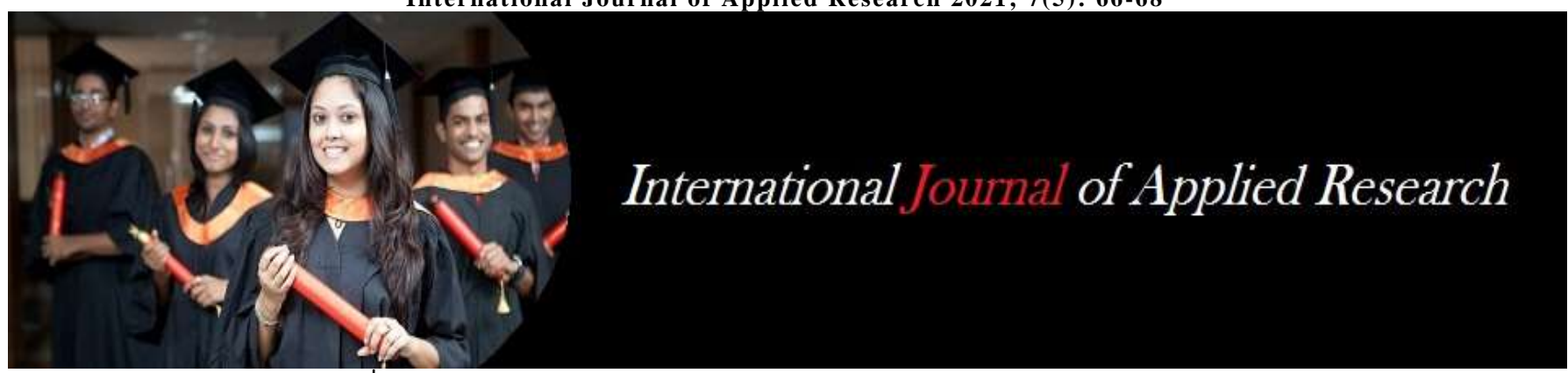

ISSN Print: 2394-7500

ISSN Online: 2394-5869

Impact Factor: 8.4

IJAR 2021; 7(5): 66-68 www.allresearchjournal.com

Received: 15-02-2021

Accepted: 02-04-2021

\section{Caroline Satur}

Principal, M.L.B.G.M.G.H.S. School, Bilaspur, Chhattisgarh, India

Dr. Sunil Gouraha Sports Officer, Rajiv Gandhi P.G. Govt. College,

Ambikapur, Sarguja, Chhattisgarh, India
Corresponding Author: Caroline Satur

Principal, M.L.B.G.M.G.H.S. School, Bilaspur, Chhattisgarh, India

\section{Combatting the challenge of COVID-19 through health, hygiene and wellness}

\section{Caroline Satur and Dr. Sunil Gouraha}

\author{
Abstract \\ "It is health that is real wealth and not pieces of gold and silver."
}

Mahatma Gandhi

As the Coronavirus-COVID-19 spreads and communities respond with increasing protective measures, we must be mindful of the need to maintain our health and wellness through establishing new routines and practices to support healthy living.

Social distancing and shelter in place orders are changing the way we learn, work, socialise and ultimately how we take care of ourselves. With the shifts and changes to our daily life coupled with looming uncertainty about the future, many of us are feeling anxious and stressed. It's now very necessary to focus only on how to care for ourselves and maintain our health and wellness during these difficult times, thus strengthening our immune system.

Health is a state of being, whereas wellness is the state of living a healthy lifestyle. Health refers to physical, mental, and social well-being; wellness aims to enhance well-being. Wellness is a concept at the forefront of health promotion. It has practical and therapeutic benefits applicable across a plethora of life domains. Existing literature has examined the phenomenon of wellness utilising subjective selfreport; however, there is a gap in the literature in terms of objective measures of wellness. Given the link between health and wellness, it is critical to examine wellness domains as they correlate with overall health. Due to the complexity of wellness and its importance in regard to individual's health, it is imperative to examine wellness not only from a subjective basis, but also in conjunction with objective explorations. Thus, the aim of this paper is to: 1) provide a comprehensive view of wellness and 2) propose new research directions in health-related research in combatting the challenge of covid19 through health, hygiene and wellness.

Keywords: Combatting, COVID-19, challenge, health, hygiene, wellness, immune system, subjective measures, objective measures

\section{Introduction}

"The secret of crisis management is not good vs. bad, it's preventing the bad from getting worse." - Ken Matos

The spread of the novel coronavirus-COVID-19, has turned our daily lives upside down. Instead of focussing on what we can't do, we need to focus on how we can survive and maybe even thrive during this unsettling time. At this trying time we all need to know that attending to different dimensions of health and well-being will not only help us remain grounded during times of change, but also it will enhance our ability to help others.

\section{The main areas of health and wellness}

\section{Physical Wellness}

"Your body is your most priceless possession. Take care of it." - Jack Lalane

Living under COVID-19 restrictions underscores the importance of being physically fit and healthy, which helps prevent infection. Lack of physical fitness slackens mental health issues because of uncertainty and stress. Therefore, in addition to preventive measures, such as frequent hand washing, social distancing, and self-isolation, individuals need to safeguard their overall physical health through physical wellness activities.

There is convincing evidence that physical activity, nutritional wellness and emotional wellness can improve walking, balance, fatigue, depression, and quality of life in people. There are also benefits for cognition, anxiety, and pain. Vascular comorbidities are common and have a major effect, and may even worsen the severity of COVID-19. 
Evidence from my colleague, Mr. Shiv Prasad Chauhan, who is a health conscious personality, indicates that exercise and physical activity reduce the prevalence and severity of conditions. We recommend that all people, very specially the weaker ones, reinforce the importance of sitting less and moving more on a daily basis by engaging in lifestyle physical activity and/or exercise amid the pandemic and after. Physical activity has many benefits, including on psychological and physical health, such that maintaining and/or increasing physical activity among people could have substantial benefits during the COVID-19 pandemic.

\section{The importance of Exercise for Physical Fitness during COVID-19}

"Increased physical activity enhances positive energy." Lailah Gifty Akita

This pandemic has forced many of us to spend more time at home, sitting down and abandoning our regular exercise routines. Experts are warning that this sudden change of behaviour towards a more sedentary lifestyle is putting our health at risk. The World Health Organisation is renewing the call-to-action that we stay active in line with the established recommendations for physical activity. At a time like this, it's very important for people of all ages and abilities to be as active as possible. WHO's 'Be Active' campaign aims to help you do just that - and to have some fun at the same time.

Regular physical activity benefits both the body and mind. It can reduce high blood pressure, help manage weight and reduce the risk of heart disease, stroke, type 2 diabetes, and various cancers - all conditions that can increase susceptibility to COVID-19. It also improves bone and muscle strength and increases balance, flexibility and fitness. For older people, activities that improve balance help to prevent falls and injuries.

Regular physical activity can help give our days a routine and be a way to stay in contact with family and friends. It's also good for our mental health - reducing the risk of depression, cognitive decline and delay the onset of dementia - and improve overall feelings.

\section{Nutritional Wellness \\ "To eat is a necessity, but to eat intelligently is an art." - La Rochefoucald}

Nutritional wellness is the celebration and education of cooking, and healthy food choices, its impact on mental health, and exploring the physical and emotional relationship humans have with food.

The dietary factors and eating a healthy diet, being physically active, managing stress, and getting enough sleep are not only critical to keeping our immune system strong but can also reduce the risk of coronavirus infection. In the face of current uncertainties, we also offer some strategies and resources to help maintain some of these practices. Do what you can, and in some cases (if you can spend some time in the kitchen or get some exercise) try to have some fun along the way!

For many, the COVID-19 pandemic has been a time of uncertainty and powerlessness; having control over diet is empowering and offers the opportunity for experimenting with home meal preparation and increased time for family meal sharing and conversation.

\section{Immunity-Boosting Foods}

"Tell me what you eat, and I will tell you what you are." G.K. Chesterton
COVID-19 infections can only be managed or reduced by maintaining social distancing, personal hygiene and immunity-boosting functional foods. Any pathogen mainly virus can quickly enter by contamination and gradually affect the organs, resulting in the death of a person. Anyways that would be difficult if there is a secure immunity system which is the only option, being healthy by adding immunity-boosting foods which are not only cheap and best but readily available in our daily diet. In this COVID-19 phase, Indians can exclusively rely on traditional foods as immunity elevator.

Some of the most important foods as immunity boosters that must be compulsorily included in our diet during this period are: Turmeric, Cumin, Coriander, Garlic, Cinnamon, Ginger, Black pepper, Cloves, Curry leaves, Mint leaves, Coriander leaves, Fenugreek seeds, Cardamom, Black Cumin, Amla, Ajwain, Green tea, Tulsi, Honey, Yoghurt, Almond, Groundnut, Tomato, Lemon, orange and Neem leaves. An adequate intake of zinc, iron, and vitamins like Vitamin A, B6, B12, C, D and E are essential for the maintenance of immune function. It is good to keep ourselves healthy by boosting our immunity with these essential boosters:

- Zinc plays an essential role to enhance our immunity. It is found in chickpeas, lentils, watermelon seeds, hemp seeds, beans, oatmeal, cashew, curd, dark chocolate

- Iron plays an important role in immune function. A diet containing too little iron can cause anaemia and weaken the immune system. It is found in fortified breakfast cereals, cooked oysters, white beans, dark chocolate, organ meats, soybeans, lentils and spinach.

Vitamins are considered essential nutrients-because acting in concert, they perform hundreds of roles in the body. They help shore up bones, heal wounds, and most of all they bolster our immune system. Therefore it is very necessary to include these in our diet:

- High vitamin A like sweet potatoes, carrots, fish (tuna), winter squashes, dark leafy greens, cantaloupe, lettuce, bell peppers, pink grapefruit, avocado and broccoli.

- Vitamin B6 like chickpeas, fruits (other than citrus), potatoes, salmon and tuna.

- Vitamin B 12 like dairy products, eggs, fortified cereals, meat, poultry, sea-food (e.g., clams, trout, salmon, haddock, tuna). Liver, canned, non-fat plain Greek yogurt and low-fat milk.

- Vitamin C like fruit (e.g., cantaloupe, citrus fruits, kiwifruit and strawberries), avocado, Juices (e.g., oranges, grapefruit, and tomato), vegetables (e.g., broccoli, Brussels sprouts, peppers, and tomatoes).

- Vitamin D like eggs, fish (e.g., herring, mackerel, salmon, trout, and tuna), fish oil and cod liver oil, fortified dairy products, fortified margarine, fortified orange juice, fortified plant-based beverages (e.g., soy, rice, and almond), fortified ready-to-eat cereals and mushrooms.

- Vitamin E like fortified cereals and juices, avocado, green vegetables (e.g., spinach and broccoli), nuts and seeds, peanuts and peanut butter and vegetable oils.

Drinking water regularly and staying well hydrated also helps our immune system 


\section{Emotional Wellness}

"I am not afraid of storms for I am learning how to sail my ship." - Amy March

Emotional wellness leads us to understand the roots of our emotions, to react to situations in a way that can teach us more about ourselves and others, and to respond to life's inevitable ups and downs with far greater confidence and equilibrium. We must learn how to experience our emotions fully and to deal with them creatively in order to achieve a richer, fuller life.

Fortunately, the very behaviours and skills that can be used to improve emotional well-being are the skills that can help people cope with the anxiety, increased isolation, and uncertainty that many are experiencing during the COVID19 pandemic. We can be emotionally well by:

- Having the ability to talk with someone about our emotional concerns and share our feelings with others

- Saying "no" when we need to without feeling guilty

- $\quad$ Feeling content most of the time

- Feeling we have a strong support network i.e. people in our life that care about us

- Being able to relax, and feeling good about who we are

- Develop a positive mind set by giving ourselves a break, remembering our good deeds, spending time with friends and forgiving ourselves.

\section{Ayurveda and yoga for protecting and boosting immunity}

"Ayurveda is a sister philosophy to yoga. It is the science of life or longevity and it teaches about the power and the cycles of nature, as well as the elements." Christy Turlington

As the world struggles to find a cure for Covid-19, the best remedy is to boost the body's immune system which will help minimise the effects, and hasten the recovery from the disease for those infected. Usage of turmeric, cumin, coriander and garlic in cooking, besides taking $10 \mathrm{gm}$. of chyavanprash in the morning. Jaggery, fresh lemon juice too can be helpful in the fight against Covid-19. Ayurvedic herbs such as tulsi, cinnamon, black pepper, shunthi (dry ginger) and raisins and regular yoga are potent aids to increase the body's immunity against harmful viruses.

Sanchit Sharma, executive director of herbal productsmanufacturer AIMIL Pharma said, "Immunity will be 'our saviour' against the virus and a healthy immune system will help in recovery from the coronavirus infection." The firm offers immunity enhancer herbal drug Fifatrol, a multi-drug combination of classical ayurvedic medicines and herbs like mrityunjay rasa, sanjeevani vati, tulsi and giloe.

"The idea is that if you don't have a potent weapon to combat the enemy, a strong and effective shield is the best bet to protect yourself."

'Yoga adds years to our life, and life to our years.' - Yoga during the Pandemic

As life swings back to the new normal after the lockdown has lifted, we are faced with newer challenges. The biggest one is stepping out of our homes to resume our work life in times when COVID-19 cases in India have not even ceased to multiply. The only one thing that can guard us against the COVID-19 pandemic other than wearing a mask, using a hand sanitiser, maintaining social distancing and getting a Complete Health Insurance is our very own immune system! It is a pre-requisite to keep it strong and what could be a better way to do so naturally than through some easy yoga poses. Just like a normal walk in the park or 30 minutes of hard-core gym exercising, yoga brings its own flavour and benefits to life, which can be performed by people of all ages, and provides us with a holistic sense of health, which is especially required during these hard times. "Yoga means addition. Addition of energy, strength and beauty to body, mind and soul." - Amit Ray

The best asanas that will benefit us during this pandemic are: Trikonasana (Triangle pose), Uttanasana (Forward Fold), Bhujangasana (Cobra pose), Shishuasana (Child pose), Matsyasana (Fish pose), Viparita Karani (Legs up the wall), Anand Balasana (Happy baby pose).

\section{Personal hygiene can help to reduce the spread of COVID-19 and flatten the epidemic curve}

In the ongoing battle to contain the spread of Covid-19, every measure will help to prevent its spread, from border controls to social distancing recommendations and even personal hygiene habits. We need to follow these good hygiene practices to protect ourselves against COVID-19, to reduce its spread and thus flatten the epidemic curve:

- We must regularly and thoroughly clean our hands with an alcohol-based hand rub or wash them with soap and water, which eliminates germs including viruses that may be on our hands.

- We must avoid touching our eyes, nose and mouth. Hands touch many surfaces and can pick up viruses. Once contaminated, hands can transfer the virus to our eyes, nose or mouth. From there, the virus can enter our body and infect us.

- We must cover our mouth and nose with our bent elbow or tissue when we cough or sneeze. Then dispose of the used tissue immediately into a closed bin and wash our hands. By following good 'respiratory hygiene', we protect the people around us from viruses, which cause colds, flu and COVID-19.

- We must clean and disinfect surfaces frequently especially those which are regularly touched, such as door handles, taps and phone screens.

\section{Conclusion}

The need for this crucial phase is to stay positive-minded, always alert, and ready to eat healthy food. These are the tools that always keep human beings active and healthy. So a healthy immune system and a sharp mind set up harmoniously may help us to combat this phase of COVID19. Positive mental health will make it possible to realise our full potential, to work productively, to make a meaningful contribution to our community, or handle the stress that comes with life, to live life as normal as possible, as happy as possible, thus giving hope to all.

\section{References}

1. Sharma A, Madaan V, Petty FD. Exercise for mental health. Primary care companion to the Journal of clinical psychiatry 2006;8(2).

2. Swapan Banerjee, Saroj Srivastava, Ashim Kumar Giri. Possible nutritional approach to cope with COVID-19 in Indian perspective.

3. World Health Organisation. Q\&A on physical activity at home during COVID-19. Published on 16 April 2020.

Websites: https://ww.artofliving org>yoga>health-andwellness

https://www.who.int>diseases >novel-coronavirus-2019 